\title{
COMMENTARY
}

\section{How deficient are vitamin D deficient critically ill patients?}

\author{
Paul Lee* \\ See related research by Amrein et al., http://ccforum.com/content/15/2/R104
}

\begin{abstract}
Vitamin D deficiency is highly prevalent among critically ill patients and may be associated with adverse outcomes. Failure of conventional vitamin D supplementation in correcting deficiency has called for studies to evaluate the efficacy and safety of a highdose regime in critically ill patients. High-dose vitamin D supplementation that corrects a deficient state effectively and safely allows for intervention studies to be undertaken to determine the impact of vitamin $D$ on morbidity and mortality in critically ill patients.
\end{abstract}

Vitamin D research has entered a renaissance in the past decade, with growing awareness of its pleiotropic actions beyond musculoskeletal health. Vitamin D deficiency is now implicated in the pathogenesis of a wide range of conditions, including infection, vasculopathy, metabolic disorders and cancer, and the therapeutic potential of vitamin $\mathrm{D}$ is a topic of intense interest. In the current issue of Critical Care, Amrein and colleagues report the efficacy and safety of a single dose of 540,000 units cholecalciferol (vitamin $\mathrm{D}_{3}$ ), given orally/enterally, to critically ill patients [1].

Vitamin D research in acute critical care is in its infancy, due to the traditional bias of vitamin D deficiency being a chronic condition. This belief has been overturned by recent studies associating vitamin D deficiency with acute life-threatening hypocalcaemia, cardiac failure and increased mortality in critically ill patients $[2,3]$. Whether vitamin D replacement improves outcomes in critically ill patients is unknown.

Vitamin D replacement in critically ill patients is theoretically problematic. Oral and enteral formulations

*Correspondence: pcylee@gmail.com

Department of Diabetes and Endocrinology, Princess Alexandra Hospital, School of Medicine, University of Queensland, 199 Ipswich Road, Woolloongabba, Brisbane, Queensland, Australia 4102 may be ineffective due to malabsorptive processes arising from gastrointestinal oedema and inflammation. The intramuscular route is relatively contraindicated in patients with coagulopathy or in patients receiving anticoagulants. Intravenous supplementation up to 500 units daily in parenteral feed, more than doubling the conventional regime, failed to correct deficiency [4]. The failure to achieve vitamin D sufficiency in early studies has indicated the need for an alternative regime, but the efficacy of high-dose vitamin D supplementation in critically ill patients has only been reported recently $[1,5]$.

The definition of vitamin D sufficiency in the general population is a subject of ongoing debate. The proposed optimal vitamin D level ranges from 20 to $>32 \mathrm{ng} / \mathrm{ml}$. While the optimal level in critical illness is yet to be defined, applying these cut-off points means a single dose of 540,000 units cholecalciferol, used in the current study [1], is capable of restoring vitamin D sufficiency in critically ill patients as early as within 24 hours of administration (mean 25-hydroxyvitamin D (25(OH)D) $>20 \mathrm{ng} / \mathrm{ml}$ ) and certainly by 1 week (mean $25(\mathrm{OH}) \mathrm{D}$ $>38 \mathrm{ng} / \mathrm{ml}$ ). These findings are similar to those reported by another recent study demonstrating efficacy of 120,000 units in divided doses [5].

The increment of $25(\mathrm{OH}) \mathrm{D}$ in the current study ( $22 \mathrm{ng} / \mathrm{ml}$ by day 3 ) stands in contrast to that reported in the general population. The mean rise in $25(\mathrm{OH}) \mathrm{D}$ 3 days after a similar single dose $(300,000$ to 600,000 units) of cholecalciferol was two or three times higher (40 to $60 \mathrm{ng} / \mathrm{ml})$ in community-dwelling individuals $[6,7]$. While baseline vitamin D status and obesity may determine response to vitamin D supplements [8], baseline $25(\mathrm{OH}) \mathrm{D}$ concentrations were not markedly different (13 to $15 \mathrm{ng} / \mathrm{ml}$ ) and the reported mean body mass index was $<30 \mathrm{~kg} / \mathrm{m}^{2}$ in these studies.

These intriguing differences have shed light on the pathogenesis of vitamin $\mathrm{D}$ deficiency in critical illness. Lesser increments in 25(OH)D concentration in critically ill patients, as observed in the current study, may relate to impairment in absorption, hydroxylation or vitamin D transport. Another hypothesis is an increase in tissue vitamin D requirement during critical illness, resulting in 
heightened conversion of 25(OH)D to active 1,25dihydroxyvitamin D on a tissue level [3]. This is supported by the more severe degree of secondary hyperparathyroidism at baseline and the surge in 1,25-dihydroxyvitamin D concentration shortly after vitamin D replacement in the critically ill population.

Collectively these results suggest a higher replacement dosage may be required in critically ill patients compared to the general population, implying critically ill patients may be more deficient than the measured serum 25(OH)D concentrations indicate. Future studies should evaluate changes in vitamin D metabolites, their binding proteins and the parathyroid axis following different dosing regimes, to determine how vitamin D metabolism, tissue requirement and renal handling of metabolites are affected during critical illness.

If critically ill patients are profoundly deficient in vitamin $\mathrm{D}$ due to increased tissue requirement for this pleiotropic hormone for immune defence and metabolic regulation, does vitamin $\mathrm{D}$ treatment improve outcome? This is reminiscent of the growth hormone story, with similar enthusiasm over the potential benefits of growth hormone in critical illness a decade ago, which ended in disappointment when studies showed that high-dose growth hormone treatment increased mortality [9].

Is high-dose vitamin $\mathrm{D}$ supplementation safe in critically ill patients? The current study revealed no occurrence of hypercalcaemia in any patients, as supported by similar safety data in the general population. A recent randomised controlled trial surprisingly revealed an increased risk of falls and fractures in communitydwelling women treated with a single dose of 500,000 units oral cholecalciferol [10], thus raising safety concerns surrounding high-dose supplementation, independent of hypercalcaemia. Causes of this unexpected harm are unclear but could be related to stunning from the ultra high dose and protective upregulation of the enzyme 25-hydroxyvitamin D-24-hydroxylase, which catabolises 1,25-dihydroxyvitamin $\mathrm{D}$, thus paradoxically reducing its tissue level [11]. A more physiologic regime consisting of more frequent dosing of lesser amounts of vitamin D may be similarly effective and should be tested in critically ill patients.

There is currently tantalising circumstantial evidence supporting a therapeutic role for vitamin D in critical illness. An effective vitamin D dosing regime will set the stage for undertaking intervention studies to investigate the impact of vitamin D supplementation on outcomes in critical illness. We wait eagerly for vitamin $\mathrm{D}$ to declare its true identity: is it a novel pleiotropic saviour, or another bystander in critical illness?

Abbreviations

25(OH)D, 25-hydroxyvitamin D.

\section{Competing interests}

The author declares that he has no competing interests.

\section{Published: 19 April 2011}

\section{References}

1. Amrein K, Sourij H, Wagner G, Holl A, Pieber TR, Smolle K, Stojakovic T, Schnedl C, Dobnig $H$ : Short-term effects of high-dose oral vitamin $D_{3}$ in critically ill vitamin D deficient patients: a randomized, double-blind, placebo-controlled pilot study. Crit Care 2011, 15:R104.

2. Lee P, Eisman JA, Center JR: Vitamin D deficiency in critically ill patients. NEngl J Med 2009, 360:1912-1914.

3. Lee P, Nair P, Eisman JA, Center JR: Vitamin D deficiency in the intensive care unit: an invisible accomplice to morbidity and mortality? Intensive Care Med 2009, 35:2028-2032.

4. Van den Berghe G, Van Roosbroeck D, Vanhove P, Wouters PJ, De Pourcq L, Bouillon R: Bone turnover in prolonged critical illness: effect of vitamin D. J Clin Endocrinol Metab 2003, 88:4623-4632.

5. Mata-Granados JM, Vargas-Vasserot J, Ferreiro-Vera C, Luque de Castro MD, Pavon RG, Quesada Gomez JM: Evaluation of vitamin D endocrine system (VDES) status and response to treatment of patients in intensive care units (ICUs) using an on-line SPE-LC-MS/MS method. J Steroid Biochem Mol Biol 2010, 121:452-455

6. Cipriani C, Romagnoli E, Scillitani A, Chiodini I, Clerico R, Carnevale V, Mascia ML, Battista C, Viti R, Pileri M, Eller-Vainicher C, Minisola S: Effect of a single oral dose of $600,000 \mathrm{IU}$ of cholecalciferol on serum calciotropic hormones in young subjects with vitamin D deficiency: a prospective intervention study. J Clin Endocrinol Metab 2010, 95:4771-4777.

7. Romagnoli E, Mascia ML, Cipriani C, Fassino V, Mazzei F, D’Erasmo E, Carnevale $\checkmark$, Scillitani A, Minisola S: Short and long-term variations in serum calciotropic hormones after a single very large dose of ergocalciferol (vitamin $\mathrm{D}_{2}$ ) or cholecalciferol (vitamin $\mathrm{D}_{3}$ ) in the elderly. J Clin Endocrinol Metab 2008, 93:3015-3020.

8. Lee P, Greenfield JR, Seibel MJ, Eisman JA, Center JR: Adequacy of vitamin D replacement in severe deficiency is dependent on body mass index. Am J Med 2009, 122:1056-1060.

9. Takala J, Ruokonen E, Webster NR, Nielsen MS, Zandstra DF, Vundelinckx G, Hinds CJ: Increased mortality associated with growth hormone treatment in critically ill adults. N Engl J Med 1999, 341:785-792.

10. Sanders KM, Stuart AL, Williamson EJ, Simpson JA, Kotowicz MA, Young D, Nicholson GC: Annual high-dose oral vitamin D and falls and fractures in older women: a randomized controlled trial. JAMA 2010, 303:1815-1822.

11. Beckman MJ, Johnson JA, Goff JP, Reinhardt TA, Beitz DC, Horst RL: The role of dietary calcium in the physiology of vitamin D toxicity: excess dietary vitamin $\mathrm{D}_{3}$ blunts parathyroid hormone induction of kidney 1-hydroxylase. Arch Biochem Biophys 1995, 319:535-539.

doi:10.1186/cc10126

Cite this article as: Lee P: How deficient are vitamin D deficient critically ill patients? Critical Care 2011, 15:154 